\title{
Differential neuroprotective effects of $14-3-3$ proteins in models of Parkinson's disease
}

\author{
TA Yacoubian ${ }^{\star, 1}$, SR Slone ${ }^{1}$, AJ Harrington ${ }^{2}$, S Hamamichi ${ }^{2}$, JM Schieltz ${ }^{2}$, KA Caldwell $^{1,2}$, GA Caldwell $^{1,2}$ and DG Standaert ${ }^{1}$
}

14-3-3 proteins are important negative regulators of cell death pathways. Recent studies have revealed alterations in 14-3-3s in Parkinson's disease (PD) and the ability of 14-3-3s to interact with $\alpha$-synuclein ( $\alpha$-syn), a protein central to PD pathophysiology. In a transgenic $\alpha$-syn mouse model, we found reduced expression of 14-3-3 $\theta,-\varepsilon$, and $-\gamma$. These same isoforms prevent $\alpha$-syn inclusion formation in an $\mathrm{H} 4$ neuroglioma cell model. Using dopaminergic cell lines stably overexpressing each 14-3-3 isoform, we found that overexpression of 14-3-30, $-\varepsilon$, or $-\gamma$ led to resistance to both rotenone and 1-methyl-4-phenylpyridinium, whereas other isoforms were not protective against both toxins. Inhibition of a single protective isoform, 14-3-30, by shRNA did not increase vulnerability to neurotoxic injury, but toxicity was enhanced by broad-based inhibition of 14-3-3 action with the peptide inhibitor difopein. Using a transgenic $C$. elegans model of PD, we confirmed the ability of both human 14-3-3 $\theta$ and a $C$. elegans 14-3-3 homologue (ftt-2) to protect dopaminergic neurons from $\alpha$-syn toxicity. Collectively, these data show a strong neuroprotective effect of enhanced 14-3-3 expression - particularly of the 14-3-30, $-\varepsilon$, and $-\gamma$ isoforms - in multiple cellular and animal models of $\mathrm{PD}$, and point to the potential value of these proteins in the development of neuroprotective therapies for human PD.

Cell Death and Disease (2010) 1, e2; doi:10.1038/cddis.2009.4; published online 14 January 2010

Subject Category: Neuroscience

This is an open-access article distributed under the terms of the Creative Commons Attribution license, which permits distribution and reproduction in any medium, provided the original author and source are credited. This license does not permit commercial exploitation without specific permission.

Parkinson's disease (PD) is a neurodegenerative disorder affecting more than four million older individuals in the most populous nations. ${ }^{1}$ There is currently no treatment that slows the degenerative process. Although the cause of most PD cases is unknown, substantial evidence points to a central role of the protein $\alpha$-synuclein ( $\alpha$-syn). Families with point mutations or gene multiplication of $\alpha$-syn exhibit autosomal dominant PD. ${ }^{2-6}$ In sporadic PD, $\alpha$-syn aggregates are present in Lewy bodies. ${ }^{7,8} \alpha$-Syn overexpression in cellular and animal models leads to cellular injury and death, ${ }^{9-12}$ but the mechanisms of this toxicity are poorly understood.

In an effort to identify factors contributing to $\alpha$-syn toxicity, we have previously evaluated alterations in gene expression in the substantia nigra (SN) of transgenic mice overexpressing human wild-type $\alpha$-syn. ${ }^{13}$ We observed that among altered genes are those encoding the 14-3-3 proteins, a family of highly conserved proteins. There are seven mammalian 14-3-3 isoforms, comprising $1 \%$ of total brain protein, and these proteins participate in many cellular functions by mediating protein-protein interactions. ${ }^{14,15} 14-3-3 s$ has a central role in cell survival, and 14-3-3 depletion can lead to activation of proapoptotic factors. ${ }^{16}$

The observation that 14-3-3 expression was dysregulated in a rodent model of $\alpha$-syn overexpression was of particular interest because of other evidence linking 14-3-3s to PD. 14-3-3s share structural homology with $\alpha$-syn, ${ }^{17}$ and coaggregate with $\alpha$-syn in Lewy bodies in human PD $^{18}$ and in a mouse PD model. ${ }^{19} 14-3-3$ and $\alpha$-syn can be co-immunoprecipitated from mammalian brains, ${ }^{11,17}$ and co-immunoprecipitation is increased in PD brains. ${ }^{20} 14-3-3 \eta$ is a negative regulator of the protein parkin, ${ }^{20}$ mutation of which leads to early onset PD. ${ }^{21}$

Together, these observations support the hypothesis that $\alpha$-syn toxicity can arise from sequestration of 14-3-3 proteins, disrupting cellular signaling, and liberating proapoptotic factors. To test this hypothesis, we have examined the expression of each 14-3-3 isoform in $\alpha$-syn transgenic mice and evaluated the effects of selective expression of the different isoforms in PD cellular models and in an invertebrate system. Our data reveal a potent and selective inhibition of toxicity by a subset of the 14-3-3 isoforms: $14-3-3 \theta,-\varepsilon$, and $-\gamma$.

\footnotetext{
${ }^{1}$ Department of Neurology, Center for Neurodegeneration and Experimental Therapeutics, University of Alabama at Birmingham, Birmingham, AL, USA and ${ }^{2}$ Department of Biological Sciences, The University of Alabama, Tuscaloosa, AL, USA

${ }^{*}$ Corresponding author: TA Yacoubian, Department of Neurology, Center for Neurodegeneration and Experimental Therapeutics, University of Alabama at Birmingham, Civitan International Research Center 525B1, 1719 6th Avenue South, Birmingham, AL 35294, USA.

Tel: + 205996 7543; Fax: + 205996 6580; E-mail: tyacoub @uab.edu

Keywords: 14-3-3; $\alpha$-synuclein; rotenone; MPP + ; Parkinson's disease; transgenic

Abbreviations: PD, Parkinson's disease; $\alpha$-syn, $\alpha$-synuclein; synT, $\alpha$-syn/truncated green fluorescent protein; LDH, lactate dehydrogenase; GFP, green fluorescent protein; SN, substantia nigra; M17, SK-N-BE(2)-M17; dat-1, dopamine transporter; PPAR $\delta$, peroxisome proliferator-activated receptor- $\delta$

Received 22.9.09; accepted 02.10.09; Edited by G Melino
} 


\section{Results}

14-3-3 isoform expression in $\alpha$-syn transgenic mice. We had previously examined changes in overall gene expression in the $\mathrm{SN}$ of $\alpha$-syn transgenic mice and found that distinct 14-3-3 isoforms were among the several hundred genes whose expression was altered in this gene array study. ${ }^{13}$ As this mouse model yields most prominent $\alpha$-syn pathology in cortical neurons, we assessed the expression patterns of 14-3-3 isoforms in cortical homogenates from 3-month-old transgenic mice, using quantitative PCR. We found that 14-3$3 \theta$ was the most significantly downregulated isoform in the cortex of the transgenic mice. This isoform was decreased by nearly $50 \%$ in transgenic mice compared to wild-type mice (Figure 1; $P<0.05$ ). 14-3-3 $\gamma$ was reduced to $60 \%$ of wild type $(P<0.05)$. Expression of $14-3-3 \varepsilon$ and $14-3-3 \sigma$ trended downward but did not reach statistical significance $(P=0.072$ for $14-3-3 \varepsilon ; P=0.088$ for $14-3-3 \sigma)$.

14-3-3 $\varepsilon,-\gamma$, and $-\theta$ reduce $\alpha$-syn inclusion formation. Because previous studies have revealed that $\alpha$-syn and 14-3-3s are colocalized in Lewy bodies, we asked whether increased 14-3-3 expression could affect $\alpha$-syn aggregation. We used an in vitro $\alpha$-syn inclusion body assay developed by McLean et al. ${ }^{22}$ Transfection of $\alpha$-syn/truncated green fluorescent protein fusion (synT) with synphilin results in cytoplasmic inclusions that immunostain for $\alpha$-syn in about $50 \%$ of $\mathrm{H} 4$ neuroglioma cells (Figure 2). We co-transfected $\mathrm{H} 4$ cells with either empty vector or a 14-3-3 isoform along with synT and synphilin and immunostained cells against $\alpha$-syn $24 \mathrm{~h}$ after transfection. $14-3-3 \varepsilon,-\gamma$, and $-\theta$ reduced the number of cells with $\alpha$-syn inclusions by $40 \%$ compared to control (Figure 2e; $P<0.001$ ). The other isoforms did not affect $\alpha$-syn inclusion formation. The reduction in inclusion formation was not secondary to reduced $\alpha$-syn expression, as expression levels of synT were comparable between control and 14-3-30-transfected cells (Figure 2f). Levels

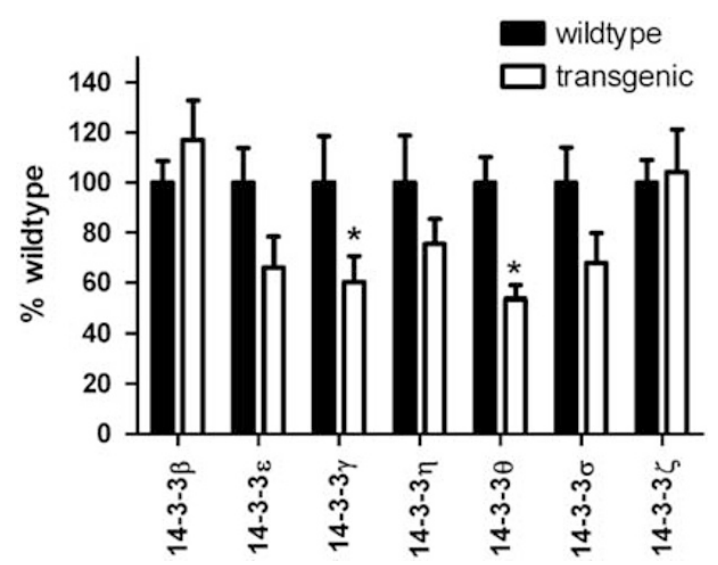

Figure 1 14-3-3 Expression in transgenic $\alpha$-syn mice and wild-type littermates. 14-3-3 $\theta$ and $\gamma$ mRNA levels were significantly reduced in $\alpha$-syn transgenic mice compared with wild-type mice. RNA was extracted from the cortex of 3-month-old transgenic mice and wild-type littermates. Primers specific to each 14-3-3 isoform were used for quantitative PCR to determine the amount of each 14-3-3 transcript. Results were normalized to GAPDH. $n=8$ per group. ${ }^{*} P<0.05$ (least-squares means test). Error bar reflects S.E.M. of endogenous monomeric $\alpha$-syn were also not reduced in 14-3-3 $\theta$-transfected cells (data not shown).

Creation of 14-3-3 stable cell lines. To examine directly the potential neuroprotective properties of 14-3-3s, we created stable cell lines overexpressing each 14-3-3 isoform. We subcloned cDNA clones for the 14-3-3 isoforms into the expression vector pcDNA3.1/V5-His. The 14-3-3 isoforms expressed from this vector are tagged with V5 and $\mathrm{His}_{6}$ epitopes at the C-terminal end. SK-N-BE(2)-M17 (M17) dopaminergic cells were transfected with each 14-3-3 vector, and stable clones were selected in the presence of G418. We created approximately 15-20 clones for each isoform. Expression of the 14-3-3 proteins was assessed by western blot analysis (Figure 3 ), and we chose 2-3 highexpressing clones for the experiments described below. We also created a control stable line by transfecting M17 cells with the empty pcDNA3.1/V5-His plasmid.

14-3-3 overexpression in these stably transfected lines did not affect the subcellular distribution of 14-3-3s. Immunostaining of naive M17 cells (Figure 4a) or control stable cells (Figure $4 b$ ) with an antibody against $14-3-3 \theta$ revealed a predominantly cytoplasmic distribution. A similar distribution was seen when we immunostained 14-3-3 $\theta$-overexpressing stable cells with either the 14-3-3 $\theta$ antibody (Figure 4c) or a V5 antibody (Figure 4f). Staining against $14-3-3 \varepsilon$ revealed similar subcellular distribution of $14-3-3 \varepsilon$ in naive M17 and 14-3-3eoverexpressing stable cells (data not shown). Subcellular distribution of $\alpha$-syn was also not altered in 14-3-3 $\theta$ stable cells as compared to control cells (Figure $4 \mathrm{~g}-\mathrm{j}$ ).

14-3-3 $\theta$ overexpression reduces rotenone toxicity. Rotenone is a pesticide that induces a parkinsonian syndrome in animals and reliably produces dose-dependent $\alpha$-syn aggregation and injury. ${ }^{23,24}$ Because 14-3-3 $\theta$ was the isoform most altered in the cortex of $\alpha$-syn transgenic mice, we first assessed the effect of 14-3-3 $\theta$ on vulnerability to rotenone. Control and 14-3-3 $\theta$-overexpressing cells were incubated with varying concentrations of rotenone in serumfree DMEM for 24, 30, and $48 \mathrm{~h}$. Cell death was assayed by lactate dehydrogenase (LDH) release into the culture media. We found that rotenone produced dose-dependent toxicity, and that $14-3-3 \theta$ cells were more resistant to rotenone than were control cells over a range of rotenone doses and time points (Figure 5). The difference between control and 14-3-3 $\theta$ cells was most prominent at $48 \mathrm{~h}$, when cell death in response to $1 \mu \mathrm{M}$ rotenone in the $14-3-3 \theta$ cells was reduced to $45 \%$ of that in control cells (Figure $5 \mathrm{c}$ ). We confirmed these findings with a second 14-3-3 $\theta$ clone (Figure 5d).

As a control for artifacts that may have been introduced during the selection of stable cell lines, we also examined the effects of transient 14-3-3 $\theta$ transfection into naive M17 cells, using transfection with EYFP for comparison. Because this method leads to low rates of transfection, we used a different approach to measure cell death. Cells were stained against V5 or green fluorescent protein (GFP) after the treatment period, and cell injury was assessed by Hoechst 33342 staining (Invitrogen, Carlsbad, CA, USA). With the rater masked to experimental condition, the nuclei of cells that 


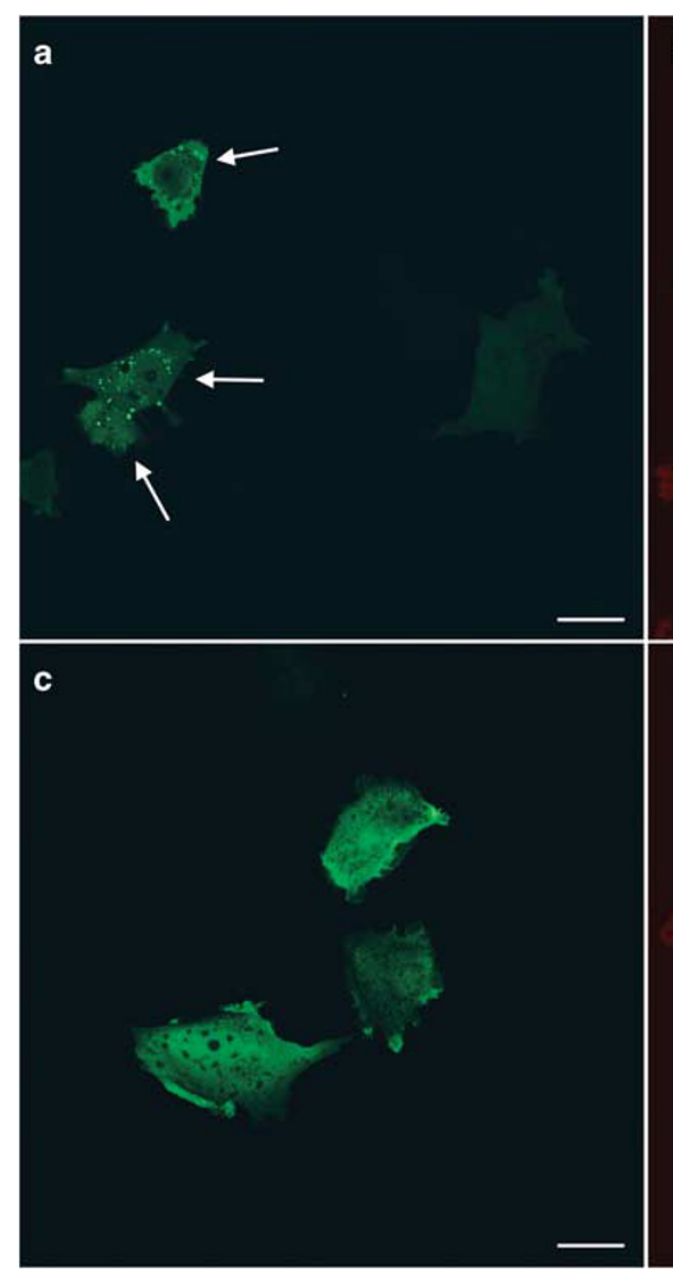

b

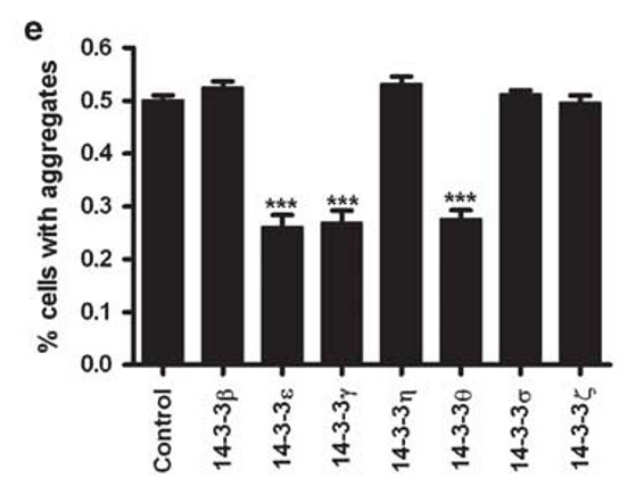

f

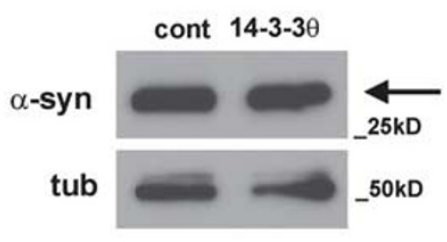

Figure 2 14-3-3e, - $\gamma$, and $-\theta$ reduce $\alpha$-syn inclusions in $\mathrm{H} 4$ neuroglioma cells. (a-d) Immunocytochemistry of $\mathrm{H} 4$ cells transfected with synT, synphilin, and empty vector $(\mathbf{a}, \mathbf{b})$ or 14-3-3 $(\mathbf{c}, \mathbf{d})$ with an antibody against $\alpha$-syn and an Alexa 488-conjugated goat anti-mouse secondary antibody (green; a, c) or a pan-14-3-3 antibody and a cy-3conjugated goat anti-rabbit secondary antibody (red; $\mathbf{b}$, d). Fewer cells transfected with 14-3-30 show $\alpha$-syn inclusions as compared to control cells. Arrows point to cells with $\alpha$-syn inclusions. Scale bar $=25 \mu \mathrm{M}$. (e) $\mathrm{H} 4$ cells were co-transfected with either empty vector or a 14-3-3 isoform along with synT and synphilin. At $24 \mathrm{~h}$ after transfection, cells were fixed and stained with a monoclonal antibody against $\alpha$-syn. Cells that stained for $\alpha$-syn were scored as positive or negative for $\alpha$-syn inclusions, with the rater masked to experimental condition. Results reflect three independent experiments with four replicates per experiment. ${ }^{* * *} P<0.001$ (Bonferroni's multiple comparison test). Error bars reflect S.E.M. (f) Expression levels of synT are not affected in $\mathrm{H} 4$ cells transfected with 14-3-30. Representative western blot of total lysates from empty vector and 14-3-3 $\theta$ transfected $\mathrm{H} 4$ cells incubated with an $\alpha$-syn antibody is shown. Results were confirmed in three independent experiments. Arrow points to the $\sim 32 \mathrm{kDa} \alpha$-syn/GFP fusion protein (synT). Tubulin was used as a loading control

stained for V5 or GFP were scored as normal or apoptotic. Cells transiently transfected with 14-3-3 $\theta$-overexpressing cells showed decreased cell death in response to rotenone (Figure 5e).
Given our results in the $\alpha$-syn inclusion assay, we next evaluated whether levels of insoluble $\alpha$-syn were reduced in 14-3-3 $\theta$ cells as compared to control cells in response to rotenone. Rotenone increases insoluble $\alpha$-syn both in vitro 
a

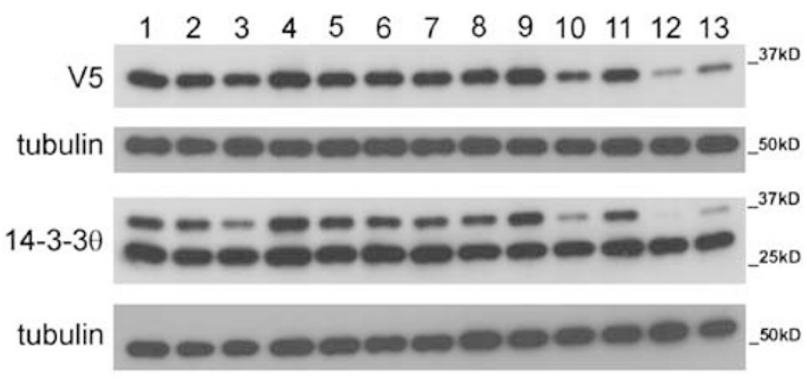

b
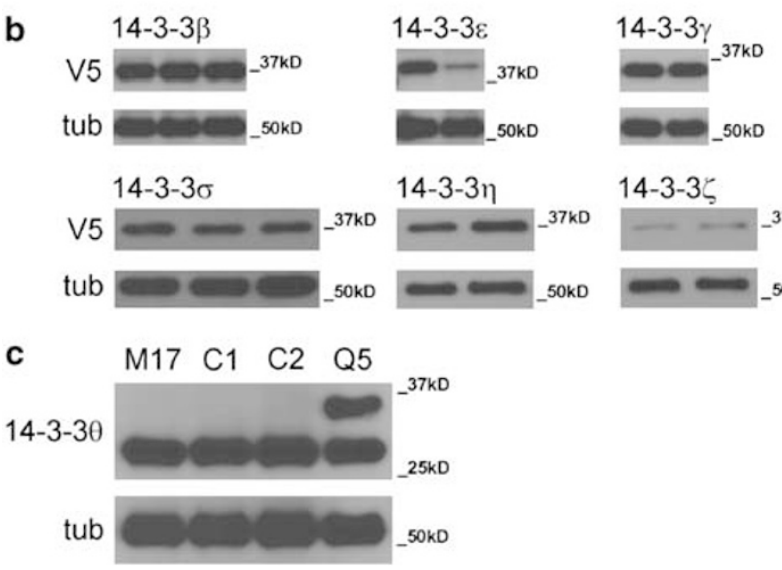

Figure 3 Stable M17 cells created to overexpress each 14-3-3 isoform. (a) 143-3 $\theta$ was subcloned into the pcDNA3.1/V5-His vector, and SK-N-BE(2)-M17 cells were transfected with V5/His-tagged 14-3-3 $\theta$ construct. Cells stably transfected with 14-3-3 $\theta$ were selected in the presence of G418. A total of 13 different clones were analyzed for their expression of 14-3-30. Protein lysates of these clones were blotted with a monoclonal antibody against V5 to detect exogenous 14-3-3 $\theta$ (top blot) or with a monoclonal antibody against 14-3-3 $\theta$ to detect total 14-3-3 $\theta$ levels (exogenous or endogenous; bottom blot). Two clones (clones 4 and 5) with high levels of 14-3-3 $\theta$ overexpression were used for the LDH experiments described below. (b) 15-20 stable clones for each of the other 14-3-3 isoforms were similarly created and analyzed for 14-3-3 overexpression by western blot against the V5 epitope tag. Two to three clones for each 14-3-3 isoform were selected for the LDH experiments based on high expression levels. Western blots of these selected clones are shown using an antibody against V5. (c) Immunoblotting against 14-3-30 reveals higher expression level of 14-3-3 $\theta$ in 14-3-3 $\theta$ stable cell line clone 5 (Q5) as compared to untransfected naive M17 cells (M17) and two control stable lines (C1, C2). Tubulin was used as a loading control for all blots

and in vivo. ${ }^{23,24}$ We treated control and 14-3-3 $\theta$ cells with $5 \mu \mathrm{M}$ rotenone for $24 \mathrm{~h}$ and then separated cell lysates into Triton $\mathrm{X}-100$ soluble and insoluble fractions. Upon rotenone treatment, insoluble $\alpha$-syn was dramatically increased in control cells, whereas a much smaller increase in insoluble $\alpha$-syn was seen in 14-3-3 $\theta$ cells treated with rotenone (Figure $5 f$ ).

We next examined whether 14-3-3 $\theta$ reduction by lentiviral shRNAs would result in increased rotenone toxicity to M17 cells. 14-3-30 shRNA lentiviruses significantly reduced 14-3$3 \theta$ in $\mathrm{M} 17$ cells as compared to control virus with the empty pLKO.1 vector (Supplementary Figure 1a). Cells infected with 14-3-3 $\theta$ shRNA did not show increased rotenone toxicity compared to control cells (Supplementary Figure 1b). These results were confirmed using another 14-3-3 $\theta$ shRNA in the same lentiviral construct (data not shown).
Differential effects of overexpression of 14-3-3 isoforms on rotenone toxicity. Given the lack of increased rotenone toxicity with 14-3-3 $\theta$ knockdown, we hypothesized that other 14-3-3 isoforms could compensate for the loss of 14-3-30. We decided to test whether overexpression of other 14-3-3 isoforms could protect against rotenone toxicity. We found significant differences between the different isoforms in terms of their ability to protect against rotenone. Cells overexpressing 14-3-3 $\varepsilon$ and $-\gamma$ showed prominent reduction in rotenone-induced toxicity (Figure $6 \mathrm{a}$ and b). Rotenoneinduced cell death at $1 \mu \mathrm{M}$ was reduced to 65 and $63 \%$ of control in the $14-3-3 \varepsilon$ and $14-3-3 \gamma$ lines, respectively. Overexpression of $14-3-3 \beta$ and $-\zeta$ also provided some protection, but not to the same extent as $14-3-3 \varepsilon,-\gamma$, or $-\theta$ (Figure $6 \mathrm{c}$ and $\mathrm{d}$ ). Rotenone-induced cell death at $1 \mu \mathrm{M}$ was reduced to 70 and $78 \%$ of control levels in 14-3-3 $\beta$ and 14-3-3 $\zeta$ cells, respectively. Differences in protection did not correlate with 14-3-3 expression levels, as 14-3-3 $\beta$ cells had higher V5 staining on western blots compared to $14-3-3 \varepsilon$ and $-\theta$ (Figure 3 ). Results for each isoform were confirmed in 1-2 other cell clones overexpressing that isoform (data not shown).

Overexpression of $14-3-3 \eta$ or $-\sigma$ did not provide protection against rotenone at any doses tested (Figure $6 e$ and $f$ ). Instead, $14-3-3 \eta$ and 14-3-3 $\sigma$ cells showed increased cell death when maintained in serum-free media $(P<0.01$ and $<0.001$, respectively) compared with control. In the presence of rotenone, 14-3-3 $\sigma$ cells showed increased toxicity compared to control cells, although the difference between 14-3$3 \sigma$ and control cells was less prominent. The $14-3-3 \eta$ cells showed a nonsignificant trend toward increased toxicity in the presence of rotenone compared to control cells. These findings suggest that the $14-3-3 \eta$ and $-\sigma$ cells were more sensitive to serum deprivation per se and that the overexpression of these proteins does not confer any specific resistance to rotenone. The results for $14-3-3 \eta$ and $-\sigma$ were confirmed in 1-2 other cell clones overexpressing that isoform (data not shown).

Difopein promotes rotenone toxicity. As several 14-3-3 isoforms are protective against rotenone, we next tested whether a global competitive inhibitor of 14-3-3 function would promote rotenone toxicity. Difopein, or dimeric, fourteen-three-three peptide inhibitor, is a high-affinity 14-33 antagonist that disrupts 14-3-3/ligand interactions. ${ }^{25}$ We subcloned the difopein-EYFP sequence into the tetracycline-inducible lentiviral construct $\mathrm{pSLIK}^{26}$ to allow regulated induction of difopein, as it causes apoptosis at baseline. ${ }^{25}$ As the control, we subcloned the scrambled difopein sequence with EYFP into pSLIK. M17 cells were infected with either the difopein-EYFP lentivirus or the control-EYFP lentivirus, and infected cells were selected in the presence of hygromycin. Two days before treatment with rotenone, selected cells were treated with $10 \mu \mathrm{g} / \mathrm{ml}$ doxycycline to induce difopein (or scrambled difopein) expression, and then cells were incubated with rotenone for $30 \mathrm{~h}$. We found that cells expressing difopein showed increased sensitivity to rotenone compared to control cells (Figure 6g). 


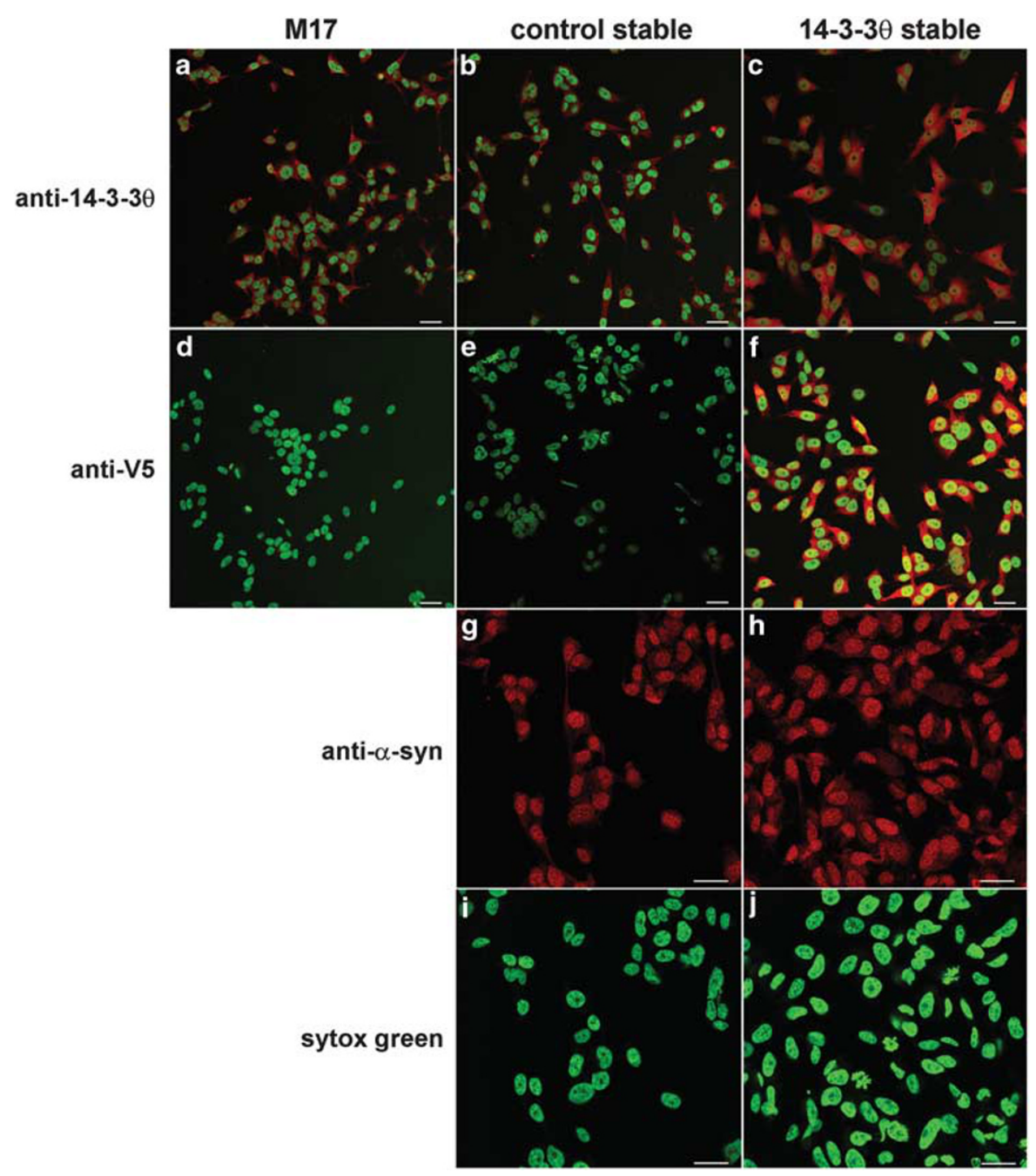

Figure 4 Subcellular distribution of V5-tagged 14-3-3 isoforms and $\alpha$-syn in stable cell lines was similar to endogenous expression in control M17 cells. (a-c) Naive M17 cells (a), control stable cells (b), and 14-3-30-overexpressing cells (c) were immunostained using a primary monoclonal antibody against 14-3-3 $\theta$ and a cy-3-conjugated goat anti-mouse secondary antibody to determine the cellular distribution of endogenous and overexpressed 14-3-30. Cells were also stained with Sytox Green to localize nuclei. 14-3-3 $\theta$ Expression in all cells was seen predominantly in the cytoplasm. (d-f) These cell lines were also stained with a primary monoclonal antibody against V5 and a cy3conjugated goat anti-mouse secondary antibody to determine the cellular distribution of exogenous V5-tagged 14-3-30. V5 staining showed similar cellular distribution as 14-3$3 \theta$ in 14-3-3 $\theta$ stable cells (f). No V5 staining was apparent in M17 (d) or control stable cells (e). Cells were stained with Sytox Green to visualize nuclei. (g-j) Control cells $(\mathbf{g}$, i) and 14-3-30 stable cells $(\mathbf{h}, \mathbf{j})$ were stained with an antibody against $\alpha$-syn to determine subcellular localization of $\alpha$-syn. Staining was apparent in both nuclear and cytoplasmic regions for both control $(\mathbf{g})$ and 14-3-30 (h) cells. Sytox Green was used to stain nuclei (i, j). Scale bar $=30 \mu \mathrm{M}$

Differential effects of overexpression of 14-3-3 isoforms on MPP ${ }^{+}$toxicity. We next tested whether the protective effects of certain 14-3-3 isoforms were restricted to rotenone or also effective against other neurotoxins that cause parkinsonian syndromes in animals. 1-Methyl-4-phenylpyridinium $\left(\mathrm{MPP}^{+}\right.$) is the active metabolite of MPTP and causes dose-dependent cell death in dopaminergic cell lines. We tested the effects of $\mathrm{MPP}^{+}$on all seven cell lines. Once again, $14-3-3 \theta,-\varepsilon$, and $-\gamma$ overexpression reduced toxicity in response to $\mathrm{MPP}^{+}$treatment for $24 \mathrm{~h}$ (Figure $7 \mathrm{a}-\mathrm{c}$ ). 14-3-3 $\beta$ and $-\zeta$ overexpression did not show any significant protection against MPP ${ }^{+}$(Figure $7 d$ and e). 14-3-3 $\eta$ and $-\sigma$ cells also showed similar levels of cell death compared with control cells in response to $\mathrm{MPP}^{+}$(Figure $7 \mathrm{f}$ and $\mathrm{g}$ ). Once again, these two sets of lines showed increased toxicity compared to control cells in serum-free media in the absence of MPP ${ }^{+}$.

Effects of 14-3-3s on $\alpha$-syn toxicity in vivo. Although both rotenone and $\mathrm{MPP}^{+}$induce $\alpha$-syn aggregation, we wished to assess more directly the potential protective effects of 14-33 s against $\alpha$-syn toxicity. We turned to a $C$. elegans model of PD, in which human wild-type $\alpha$-syn and GFP are overexpressed in dopaminergic neurons under the control of the dopamine transporter (dat-1) promoter. Transgenic C. elegans overexpressing human wild-type $\alpha$-syn show a predictable loss of dopaminergic neurons as indicated by 

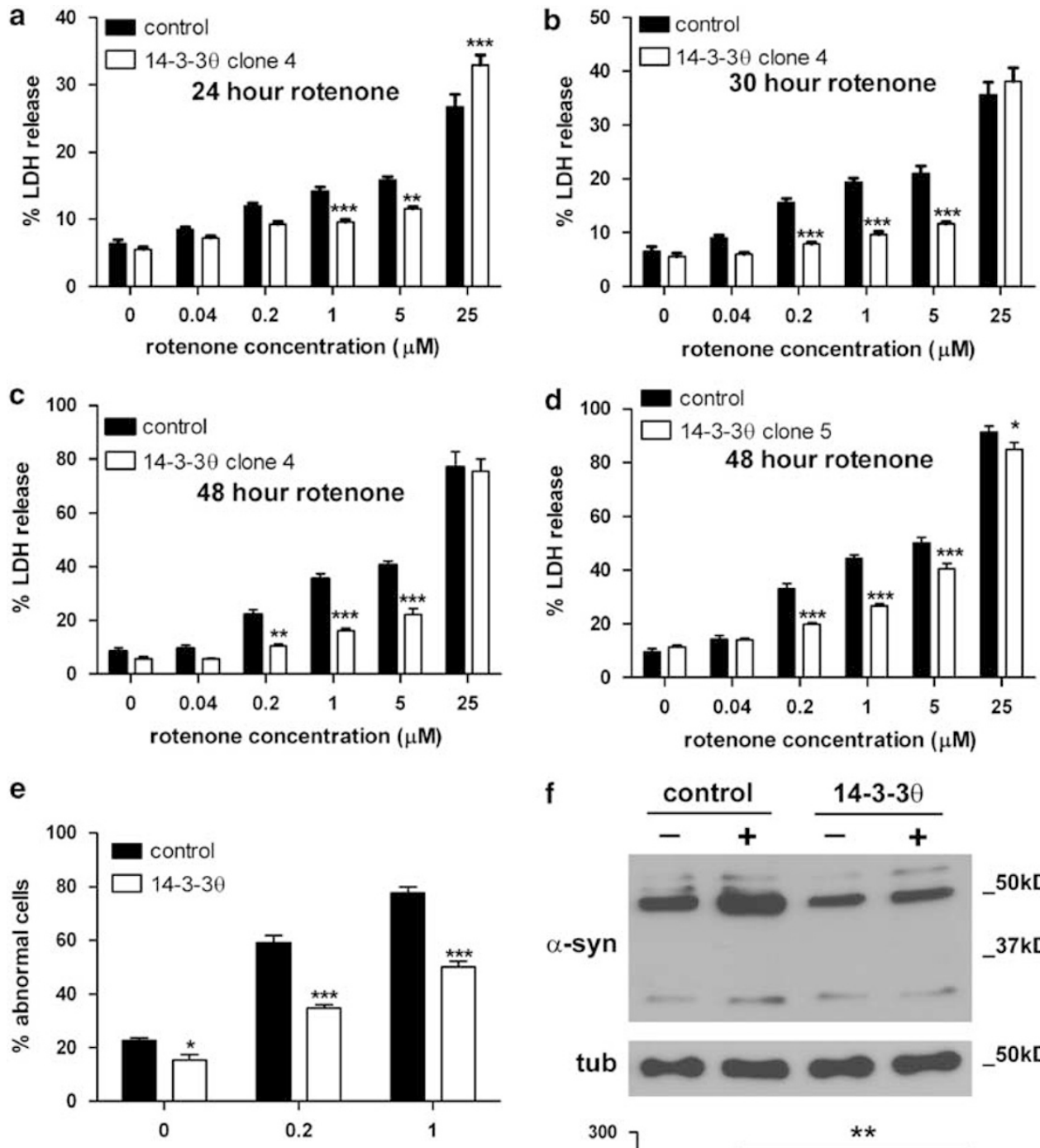

f

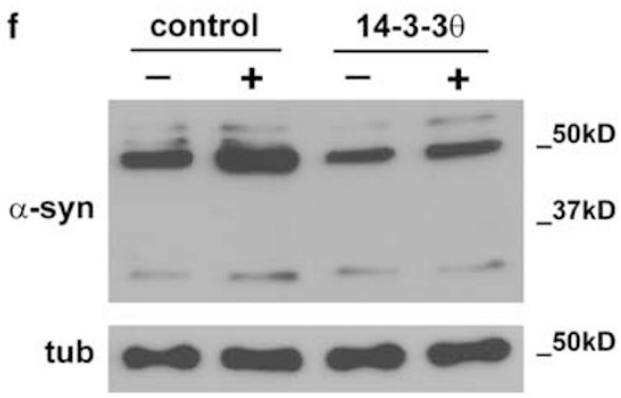

rotenone concentration $(\mu \mathrm{M})$

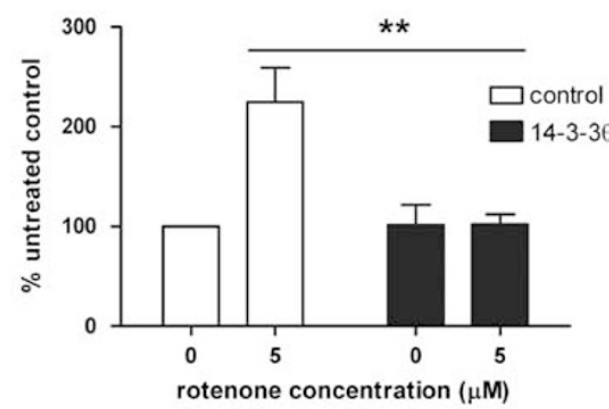

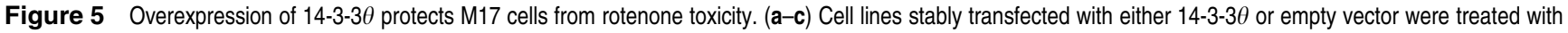
varying concentrations of rotenone for $24 \mathrm{~h}(\mathbf{a}), 30 \mathrm{~h}(\mathbf{b})$, or $48 \mathrm{~h}$ (c). Cell death was assayed by LDH release into the culture media. LDH release into media was normalized to total LDH release for each well. The 14-3-30-overexpressing line was more resistant to rotenone at several different concentrations compared to control stable cells at all time points tested. (d) At the $48 \mathrm{~h}$ time point, a second 14-3-30-overexpressing stable clone was tested to verify these results. Results reflect 2-3 independent experiments with at least two replicates per experiment. ${ }^{\star} P<0.05,{ }^{* \star} P<0.01,{ }^{* \star \star} P<0.001$ (Bonferroni's multiple comparison test). (e) To confirm these findings using an alternative cell death assay, we transiently transfected with V5/His-tagged 14-3-30 construct plasmid into naive M17 cells. Control cells were transfected with GFP. At $24 \mathrm{~h}$ after transfection, cells were treated with rotenone at $0,0.2$, or $1 \mu \mathrm{M}$ for $24 \mathrm{~h}$. Afterwards, cells were fixed and immunostained with an antibody against V5 or GFP, followed by nuclear staining with Hoechst 33342. Nuclei of transfected cells were scored as normal or showing apoptotic changes. Rater was blind to experimental condition. $n=8$ for each experimental condition. ${ }^{*} P<0.05$, ${ }^{* \star \star} P<0.001$ (Bonferroni's multiple comparison test). (f) Amount of insoluble $\alpha$-syn was reduced in $14-3-3 \theta$ cells treated with $5 \mu \mathrm{M}$ rotenone for $24 \mathrm{~h}$ compared to control cells. After rotenone treatment, cell lysates were separated into Triton X-100 soluble and insoluble fractions and blotted with an antibody against $\alpha$-syn. Representative western blot of insoluble fractions is shown. Densitometric quantification of the multiple $\alpha$-syn bands includes four independent experiments; we quantified the region between $\sim 30$ and $\sim 70 \mathrm{kDa}$ where all major bands were found. ${ }^{\star \star} P<0.01$ (Tukey's multiple comparison test). Error bars reflect S.E.M. 

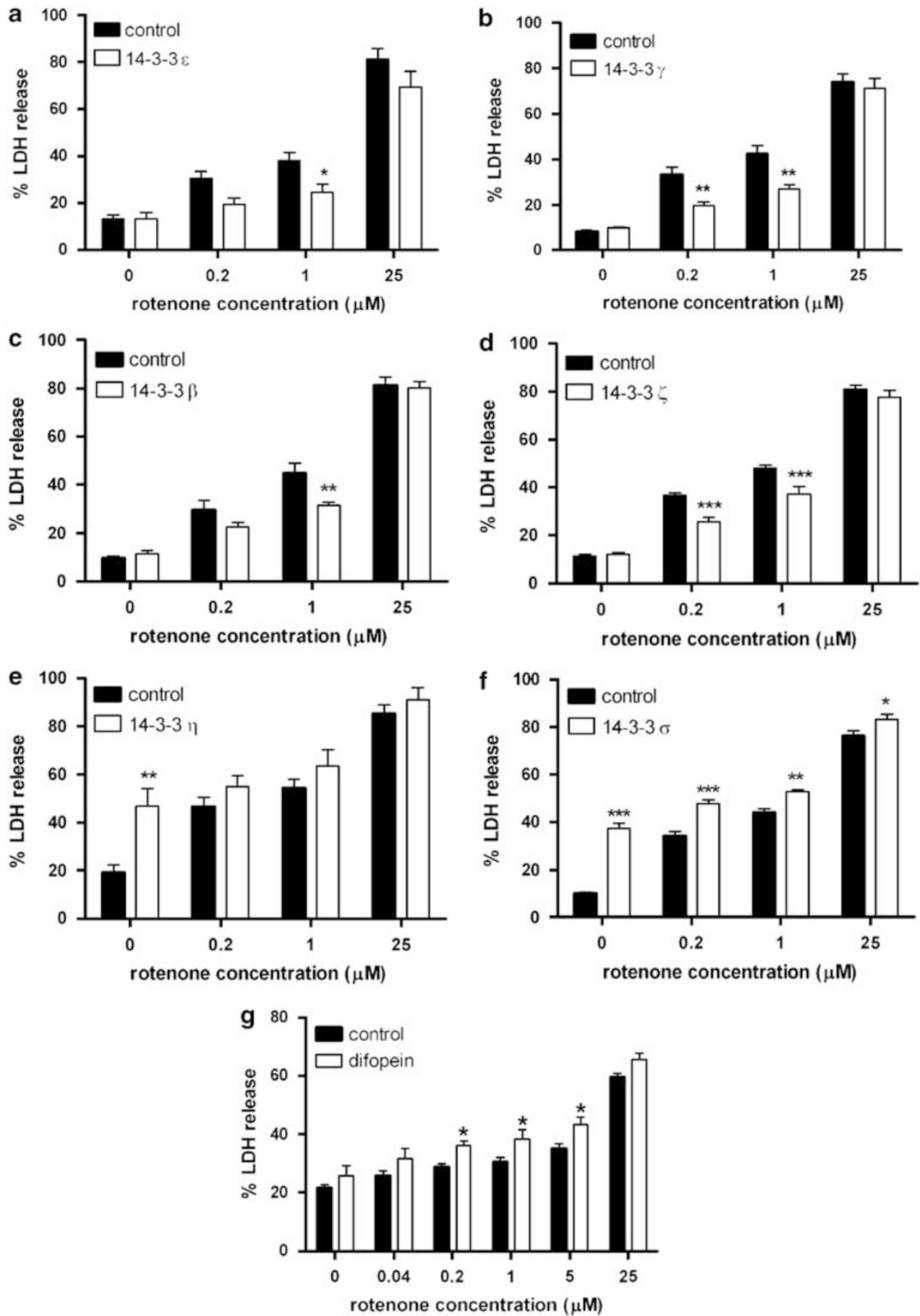

Figure 6 Overexpression of other 14-3-3 isoforms also protects against rotenone toxicity, whereas inhibition of 14-3-3s promotes toxicity. (a-f) Cell lines stably transfected with either a 14-3-3 isoform or empty vector were treated with varying concentrations of rotenone for $48 \mathrm{~h}$. Cell death was assayed by LDH release into the culture media. LDH

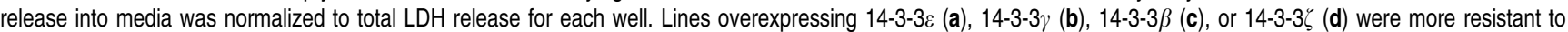
rotenone compared to control stable cells. In contrast, overexpression of 14-3-3 $\eta$ (e) and 14-3-3 $\sigma$ (f) did not protect against rotenone and showed increased toxicity at baseline. Results reflect 2-3 independent experiments with at least two replicates per experiment. ${ }^{*} P<0.05,{ }^{* \star} P<0.01,{ }^{* * *} P<0.001$ (Bonferroni's multiple comparison test). Error bars reflect S.E.M. (g) M17 cells were infected with either tetracycline-inducible difopein-EYFP lentivirus or scrambled difopein-EYFP lentivirus. After 2 days of induction by doxycycline, cells were plated and treated with increasing doses of rotenone for $30 \mathrm{~h}$, and cell death was assayed by LDH release. Difopein-expressing cells were more sensitive to rotenone compared to control stable cells. ${ }^{*} P<0.05$ (least-squares means test). Results reflect three independent experiments with at least two replicates per experiment. Error bars reflect S.E.M. 

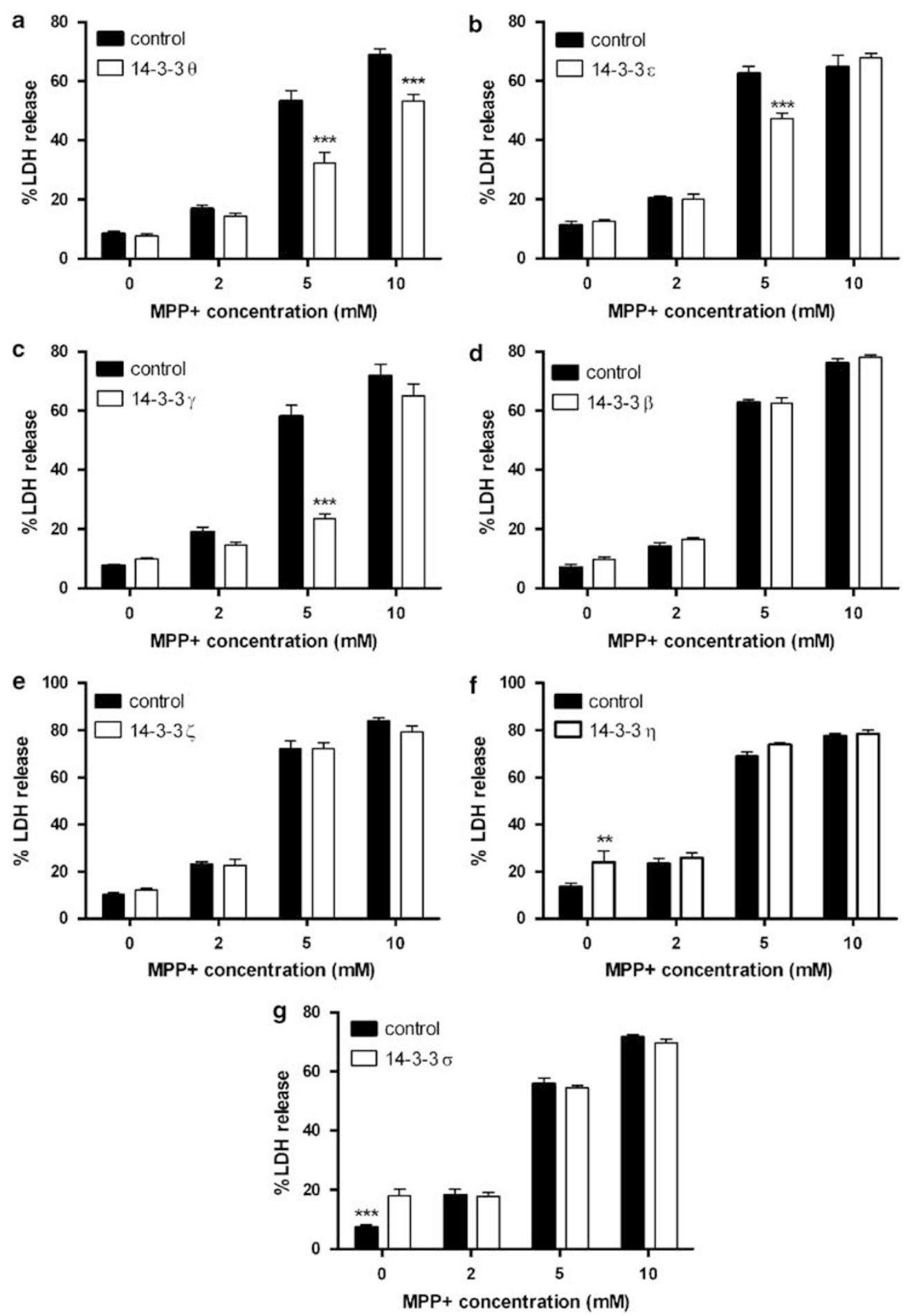

Figure 7 Overexpression of 14-3-3 $\varepsilon,-\gamma$, and $-\theta$ protects against MPP ${ }^{+}$toxicity. Cell lines stably transfected with either a 14-3-3 isoform or an empty vector were treated with varying concentrations of $\mathrm{MPP}^{+}$for $24 \mathrm{~h}$. Cell death was assayed by LDH release into the culture media. LDH release into media was normalized to total $\mathrm{LDH}$ release for each well. Lines overexpressing 14-3-3 3 (a), 14-3-3 $(\mathbf{b})$, or 14-3-3 $\gamma$ (c) were more resistant to MPP ${ }^{+}$compared to control stable cells. In contrast, overexpression of 14-3-3 $\beta$ (d) $, 14-3-3 \zeta(\mathbf{e}), 14-3-3 \eta(\mathbf{f})$, or 14-3-3 $\sigma(\mathbf{g})$ did not protect against MPP ${ }^{+}$. Results reflect 2-3 independent experiments with at least two replicates per experiment. ${ }^{* *} P<0.01$, ${ }^{\star \star \star} P<0.001$ (Bonferroni's multiple comparison test). Error bars reflect S.E.M.

alterations in cellular morphology and reduction in GFP expression. ${ }^{27}$ We created double transgenic worms in which a particular 14-3-3 isoform and $\alpha$-syn were overexpressed, both under the dat-1 promoter (Figure 8). Three separate transgenic lines were created for each 14-3-3 isoform and analyzed. We focused on $14-3-3 \varepsilon,-\gamma$, and $-\theta$, the three 

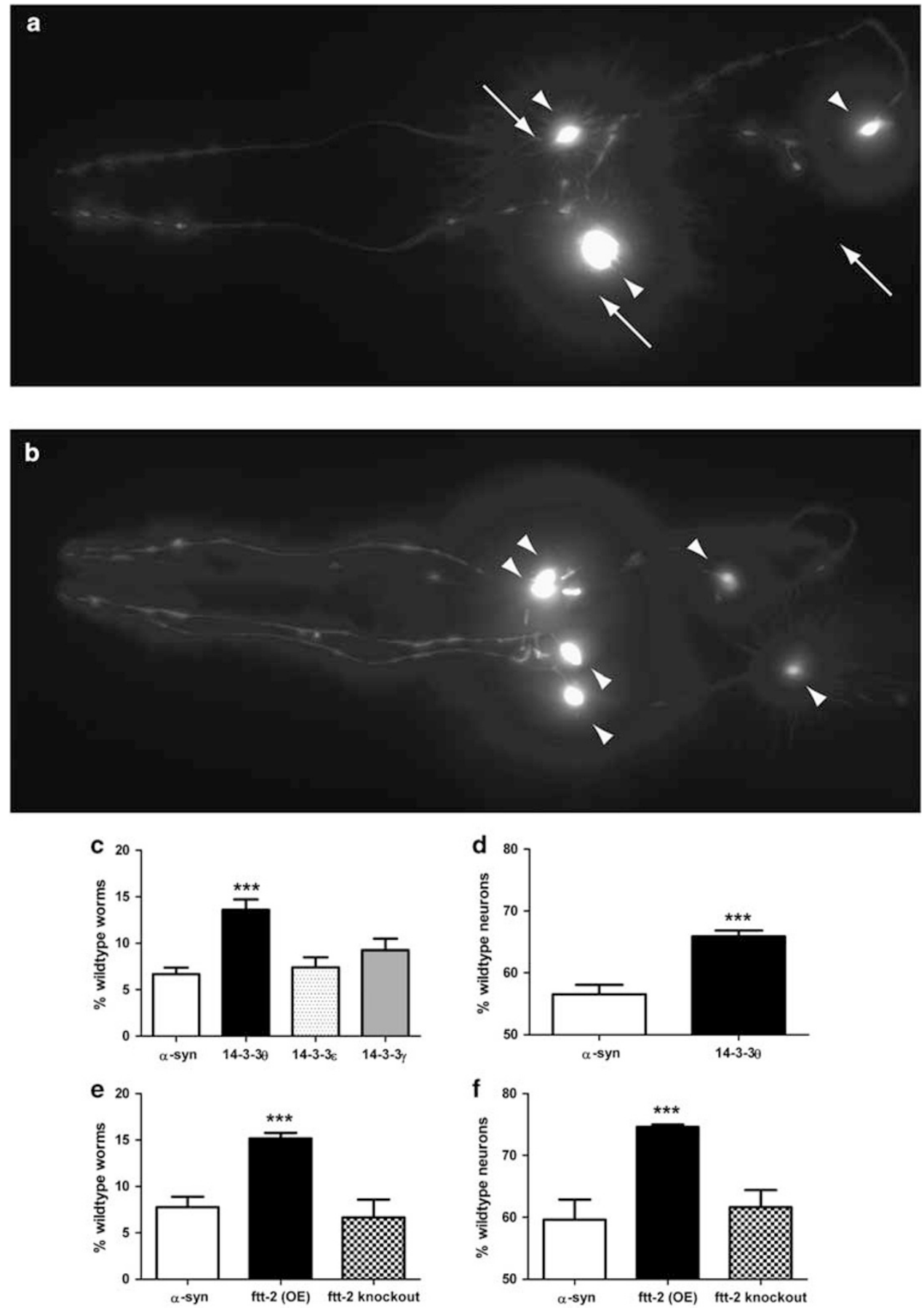

Figure 8 Overexpression of 14-3-30 protects against dopaminergic cell loss in the $\alpha$-syn transgenic $C$. elegans worm model. Expression plasmids, $P_{\text {dat- }-1:: \text { human } 14-3-}$ $3 \theta$ and $P_{\text {unc- }-54::}$ mCherry, were constructed and microinjected into the gonads of $C$. elegans strain that already expresses $\alpha$-syn and GFP (P $P_{\text {dat }-1}:: \alpha$-syn; $\left.P_{\text {dat }-1}:: G F P\right)$ and exhibits age-dependent $\alpha$-syn-induced degeneration in dopaminergic neurons. Similar double transgenic worms were created to overexpress human 14-3-3e, human 14-3-3 $\gamma$, or the worm 14-3-3 homologue ftt-2. In addition, a mutant ftt-2 knockout that overexpressed $\alpha$-syn was also created. (a) $\alpha$-Syn worm shows loss of dopaminergic neurons (only two CEP neurons and one ADE neuron remain) at day 7. Arrowheads show intact dopaminergic neuron cell bodies. Lined arrows indicate areas where dopaminergic neurons have degenerated. (b) Overexpression of 14-3-30 in the $\alpha$-syn-overexpressing line protects dopaminergic neurons from $\alpha$-syn-induced cell death. Arrowheads show six intact dopaminergic neuron cell bodies. (c, d) 14-3-30 reduced dopaminergic cell loss, but 14-3-3 $\varepsilon$ and - $\gamma$ did not. The numbers of $\alpha$-syn transgenic worms and $\alpha$-syn/14-3-3 double transgenic worms that had the full complement of six anterior dopaminergic neurons were scored at day 10 (c). The percentage of intact dopaminergic neurons per worm was also scored at day 10 for $\alpha$-syn and $\alpha$-syn/14-3-30 transgenic worms (d). (e, f) Overexpression (OE) of the worm 14-3-3 homologue ftt-2 also reduced dopaminergic cell death, but ftt-2 knockout did not enhance neurodegeneration. The percentage of worms that had the full complement of dopaminergic neurons (e) and the percentage of intact dopaminergic neurons per worm (f) were scored at day 10. For each experiment, three independent transgenic lines were scored, with 30 worms per line analyzed in triplicate experimental trials. Plotted data reflect the average of these three separate lines. ${ }^{\star \star \star} P<0.001$ (Bonferroni's multiple comparison test). Error bars reflect standard deviation 
human isoforms that reduced neurotoxicity in response to both rotenone and MPP ${ }^{+}$. In worms that overexpressed only $\alpha$-syn, we found that only $6.67 \%$ of the worms had all six anterior dopaminergic neurons present at 10 days, whereas $13.61 \%$ of worms that overexpressed human $14-3-3 \theta$ along with $\alpha$-syn had all six dopaminergic neurons at 10 days (Figure 8c; $P<0.001$ ). Likewise, the average number of intact dopaminergic neurons was significantly higher in the double transgenic 14-3-30/ $\alpha$-syn worms compared to $\alpha$-syn worms (Figure 8d; $P<0.001$ ). Similar results were seen when worms were analyzed at 7 days (data not shown). Transgenic $14-3-3 \varepsilon$ or $14-3-3 \gamma$ worms did not exhibit a significant change in dopaminergic neurodegeneration (Figure 8c).

We also investigated whether $\mathrm{ftt}-2$, the closest $C$. elegans homologue to $14-3-3 \theta$, can protect against $\alpha$-syn toxicity. Of transgenic worms that overexpress ftt-2 along with $\alpha$-syn, $15.19 \%$ retained all six dopaminergic neurons, compared to only $7.78 \%$ of $\alpha$-syn worms, at 10 days (Figure 8e; $P<0.001$ ). Average numbers of intact dopaminergic neurons were significantly higher in the $\mathrm{ftt}-2 / \alpha$-syn double transgenic worms compared to $\alpha$-syn worms (Figure 8f; $P<0.001$ ). We also tested whether knockout of $f t t-2$ affected $\alpha$-syn toxicity. There was no significant difference in dopaminergic cell loss between $\alpha$-syn worms and $\alpha$-syn/ftt- 2 knockout worms at 10 days (Figure $8 e$ and f). Semiquantitative RT-PCR was used to confirm lack of ftt-2 expression (data not shown).

\section{Discussion}

Using a diverse set of cellular and animal PD models, we have observed a remarkably consistent neuroprotective effect of several 14-3-3 isoforms. In $\alpha$-syn transgenic mice, we report prominent $\mathrm{mRNA}$ downregulation of $14-3-3 \varepsilon,-\gamma$, and $-\theta$ in the cortex, a site of intense $\alpha$-syn pathology. We found that these same isoforms reduce $\alpha$-syn inclusions in neuroglioma cells and attenuate rotenone and $\mathrm{MPP}^{+}$toxicity in stably transfected neuroblastoma cells. Both human 14-3-3 $\theta$ and its worm homologue reduced $\alpha$-syn toxicity in a $C$. elegans model. The effects of the other isoforms were less consistent: 14-3-3 $\beta$ and $-\zeta$ protected against rotenone but not $\mathrm{MPP}^{+}$, and $14-3-3 \eta$ and $-\sigma$ increased cell vulnerability to nonspecific insults. The consistency of these results suggests commonality in the mechanism of protection in each of these assays, and that the isoforms, although structurally similar, act on different effector systems.

Further support for the specific relationship between 14-3$3 \varepsilon,-\gamma$, and $-\theta$ and PD pathophysiology is provided by studies of Lewy bodies in human post-mortem brain. Using isoformspecific antibodies, we observed $14-3-3 \varepsilon,-\gamma$, and $-\theta$, as well as 14-3-3 $\zeta$ in human Lewy bodies, whereas the other isoforms were absent. ${ }^{28}$ It should be noted that we were unable to generate a 14-3-3 $\zeta$-overexpressing stable line that showed as much overexpression as lines expressing other isoforms. Therefore, it is possible that we failed to observe a broad protective effect of 14-3-3 $\zeta$ because of insufficient expression. In addition, proteomic analysis of phosphorylation-dependent $\alpha$-syn interactions revealed that $14-3-3 \varepsilon,-\gamma$, and $-\zeta$ were among those proteins that interact specifically with phosphorylated $\alpha$-syn. $^{29}$
Although earlier studies have examined the effects of 14-33 proteins in PD models, few have considered the differential effects of all the distinct isoforms. One previous study showed that $14-3-3 \varepsilon$ overexpression is protective against $\mathrm{MPP}^{+}$ toxicity in PC12 cells but did not evaluate other isoforms. ${ }^{30}$ Studies showing interactions between 14-3-3s and $\alpha$-syn have not clearly defined which isoforms are involved. ${ }^{11,17}$ Sato et $a l^{20}$ provided the most extensive evaluation of different 14-3-3 isoforms in an analysis of 14-3-3 effects on parkin function. 14-3-3 $\eta$ was the only isoform that immunoprecipitated with parkin and inhibited its ubiquitylation activity. We found that $14-3-3 \eta$ did not affect $\alpha$-syn aggregation or reduce neurotoxicity induced by rotenone or $\mathrm{MPP}^{+}$but increased sensitivity to serum deprivation. As 14-3-3 $\eta$ reduces parkin function, overexpression of $14-3-3 \eta$ could possibly be detrimental to cells by altering protein degradation. This potential mechanism does not explain our 14-3-3 $\sigma$ findings, the other isoform that promoted sensitivity to stressors, as 14-3-3 $\sigma$ was not found to bind parkin or alter its function. ${ }^{20} 14-3-3 \sigma$ has been implicated as a tumor suppressor and is inactivated in several cancers; ${ }^{14,15,31,32}$ therefore, $14-3-3 \sigma$ overexpression in cells examined by us could promote sensitivity to stressors like serum deprivation. 14-3-3 $\sigma$ expression is mainly limited to epithelial cells ${ }^{33}$ and is unlikely to be relevant to PD pathogenesis.

Currently we do not know the mechanism for the differential 14-3-3 effects observed in our studies. The different isoforms may bind to different ligands that mediate the differential neuroprotective effects. An important ligand may be $\alpha$-syn. As noted above, a proteomic study showed that $14-3-3 \varepsilon,-\gamma$, and $-\zeta$ interacted with a phosphorylated $\alpha$-syn peptide, whereas other isoforms were not detected. ${ }^{29}$ Here we show that in contrast to the other isoforms $14-3-3 \varepsilon,-\gamma$, and $-\theta$ reduced $\alpha$-syn inclusion formation. We also observed less insoluble $\alpha$-syn in $14-3-3 \theta$ cells treated with rotenone. Whether aggregation is important to $\alpha$-syn toxicity, the ability of these isoforms to interact with $\alpha$-syn may be key to their neuroprotective effects. Alternatively, the differential effects of 14-3-3s may arise from differing abilities to interact with downstream effectors. For example, $14-3-3 \varepsilon,-\theta$, and $-\zeta$ interact with Bax, whereas $14-3-3 \beta$ does not. ${ }^{34}$ Differential interactions of $14-3-3$ proteins with other apoptotic factors could also explain their differential effects.

Although $14-3-3 \varepsilon,-\gamma$, and $-\theta$ showed protection in vitro, only human 14-3-3 $\theta$ overexpression reduced toxicity in the $C$. elegans $\alpha$-syn model. It is not clear why human $14-3-3 \varepsilon$ and $-\gamma$ were not protective in this worm model. One explanation is that $14-3-3 \theta$ is more effective at reducing toxicity. Alternatively, $C$. elegans may not be able to process 14-3-3 isoforms of a different species effectively. Human $14-3-3 \theta$ is more homologous with the $C$. elegans 14-3-3 orthologs than are $14-3-3 \varepsilon$ and $-\gamma$. Indeed, we found that the worm 14-3-3 homologue $\mathrm{ftt}-2$ was also effective in reducing $\alpha$-syn toxicity. It is also possible that only human $14-3-3 \theta$ can effectively interact with worm apoptotic factors.

In this study, we observed reduced RNA expression of $14-3-3 \varepsilon,-\gamma$, and $-\theta$ in the $\alpha$-syn transgenic mouse model. Because these are the same isoforms that were protective when overexpressed, this observation raises the possibility that reduction of 14-3-3 expression may contribute to the 
progression of PD. We did attempt to examine the effect of reducing 14-3-3 $\theta$ mRNA levels directly through shRNA inhibition, but found that inhibition of this single isoform had no clear effect on vulnerability to rotenone. Similarly, ftt-2 knockout in the $C$. elegans model did not promote $\alpha$-syn toxicity. In both cases, other 14-3-3 isoforms could compensate for the loss of a single 14-3-3 isoform - six others in humans, and one other, par-5, in $C$. elegans. We did observe that the broad-spectrum 14-3-3 inhibitor, difopein, had a modest effect on sensitivity to rotenone. There are several potential explanations for the limited magnitude of this effect. First, difopein expression levels could have been limited, as higher levels are likely too toxic for cells to survive in control conditions. Second, given the differential neuroprotective effects of the 14-3-3s, the sum effect of interfering with all isoforms may not be a dramatic increase in toxicity. We are unable to test whether knockout of both ftt-2 and par-5 would promote $\alpha$-syn toxicity in the $C$. elegans model, as loss of par- 5 function is embryonically lethal. ${ }^{35}$

We hypothesize that $\alpha$-syn can disrupt 14-3-3 function through several mechanisms that may contribute to $\alpha$-syn toxicity. Previously it has been suggested that the ability of $\alpha$-syn to sequester $14-3-3$ s would promote cell death by release of apoptotic factors normally inhibited by 14-3-3s. ${ }^{11}$ We propose that $\alpha$-syn also exerts its effect at a transcriptional level to reduce the expression of functional 14-3-3 proteins: decreased 14-3-3 transcription would compound effect of $\alpha$-syn on 14-3-3 sequestration by preventing injured neurons from replenishing functional 14-3-3 stores. Functional genomic analysis of our microarray data has shown that genes whose expression is altered in $\alpha$-syn transgenic mice are predominantly involved in transcription. ${ }^{13}$

Our data point to the potential therapeutic utility of treatments that enhance 14-3-3 function or expression, especially $14-3-3 \varepsilon,-\gamma$, and $-\theta$. Several compounds that can stimulate 14-3-3 expression have been identified, including peroxisome proliferator-activated receptor- $\delta(\operatorname{PPAR} \delta)$ and PPAR ligands. ${ }^{36-38}$ In a mouse stroke model, reduction of infarct volume by rosiglitazone was blocked by siRNA knockdown of $14-3-3 \varepsilon$ and restored by increasing $14-3-3 \varepsilon .{ }^{38}$ The actions of these compounds establish the principle that small molecules can produce potent upregulation of 14-3-3 expression, and point to the possibility of developing a useful human neuroprotective agent that uses this mechanism.

\section{Materials and Methods}

Animals. $\alpha$-Syn transgenic mice originally generated by Masliah et al. ${ }^{39}$ were bred at Charles River Laboratories (Wilmington, MA, USA) to generate transgenic and wild-type littermates. The use of mice was supervised by the Massachusetts General Hospital Animal Resources Program in accordance with the PHS policy on Humane Care and Use of Laboratory Animals. Mice were killed by $\mathrm{CO}_{2}$ inhalation. Gender-matched wild-type and transgenic mice were killed at 3 or 9 months of age.

Quantitative PCR. RNA was extracted from the cortex of wild-type and transgenic mice and reverse transcribed into first-strand CDNA using the SuperScript II Reverse Transcriptase Kit (Invitrogen). Primers against each of the human 14-3-3 isoforms were designed using Primer3 (http://frodo.wi.mit.edu). Primers against 14-3-3 $\beta$ (NM_018753) were $5^{\prime}$-aaaggtcccgtgctcatacc-3' (forward) and $5^{\prime}$-gccgcctca acacattattc- $3^{\prime}$ (reverse). Primers against 14-3-3e (NM_009536) were $5^{\prime}$-ttgggtgttag cttgaggtg- $3^{\prime}$ (forward) and $5^{\prime}$-gaggagtcggcaagaatgag- $3^{\prime}$ (reverse). Primers against

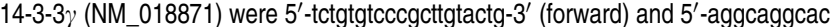
acttctcaac- $3^{\prime}$ (reverse). Primers against 14-3-3 $\eta$ (NM_011738) were $5^{\prime}$-tctagcaaatc caggtgatgg- $3^{\prime}$ (forward) and $5^{\prime}$-aggctgatggtgaaggaatg- $3^{\prime}$ (reverse). Primers against 14-3-30 (NM_011739) were 5'-aggagtgacagcacacttgg-3' (forward) and $5^{\prime}$-gttgcttctg aaaggaaacctc- $3^{\prime}$ (reverse). Primers against 14-3-3 $\sigma$ (NM_018754) were $5^{\prime}$-gtctgtcc ttcatcgcagtc- $3^{\prime}$ (forward) and $5^{\prime}$-tcctcgttgctcttctgctc- $3^{\prime}$ (reverse). Primers against 14-3-3 (NM_011740) were $5^{\prime}$-ggctagtgattggaggaaacc-3' (forward) and $5^{\prime}$-tcatatcg ctctgcctgctc- $3^{\prime}$ (reverse). Real-time quantitative PCR was performed as previously described. ${ }^{13}$ We used GAPDH (forward primer $5^{\prime}$-tggtgaagcaggcatctga- $3^{\prime}$; reverse primer $5^{\prime}$-tgctgttgaagtcgcaggag- $\left.3^{\prime}\right)$ to normalize PCR results.

$\alpha$-Syn inclusion assay. $\mathrm{H} 4$ cells were transfected with synphilin, $\alpha$-syn/synT, and either empty vector control or a 14-3-3 isoform using SuperFect transfection reagent (Qiagen, Germantown, MD, USA), as previously described. ${ }^{22}$ At $24 \mathrm{~h}$ after transfection, cells were fixed with $4 \%$ paraformaldehyde and immunostained with a monoclonal antibody against $\alpha$-syn (BD Biosciences, San Diego, CA, USA) and a secondary Alexa 488-conjugated goat anti-mouse antibody (Invitrogen). All cells stained for $\alpha$-syn were scored as positive or negative for $\alpha$-syn inclusions, with the rater blind to experimental condition.

Creation of stable cell lines. Each 14-3-3 isoform was subcloned into the mammalian expression vector pcDNA3.1/V5-His (Invitrogen). SK-N-BE(2)-M17 cells (ATCC, Manassas, VA, USA) were transfected with each isoform or empty vector using SuperFect, and selection for stably transfected cells was performed in the presence of G418 (Invitrogen). Some 15-20 clones for each isoform were selected for evaluation of 14-3-3 expression by western blotting.

Immunoblotting. Control and 14-3-3 stable M17 cells were sonicated for $10 \mathrm{~s}$ on ice in lysis buffer ( $150 \mathrm{mM} \mathrm{NaCl}, 10 \mathrm{mM}$ Tris- $\mathrm{HCl}$ (pH 7.4), $1 \mathrm{mM}$ EGTA, $1 \mathrm{mM}$ EDTA, 0.5\% NP-40, protease inhibitor cocktail (Roche Diagnostics, Indianapolis, IN, USA)) and centrifuged at $16000 \times g$ for $10 \mathrm{~min}$. Protein concentrations were determined by the bicinchoninic acid assay (Pierce, Rockford, IL, USA). Samples were boiled for $5 \mathrm{~min}$ in $4 \times$ DTT sample loading buffer $(0.25 \mathrm{M}$ Tris- $\mathrm{HCl}(\mathrm{pH} 6.8)$, $8 \%$ SDS, $200 \mathrm{mM} \mathrm{DTT}, 30 \%$ glycerol, Bromophenol Blue), resolved on $15 \%$ SDSpolyacrylamide gels, and transferred to PVDF membranes. Blots were blocked in $5 \%$ non-fat dry milk in TBST ( $25 \mathrm{mM}$ Tris- $\mathrm{HCl}$ (pH 7.6), $137 \mathrm{mM} \mathrm{NaCl}, 0.1 \%$ Tween 20) for $1 \mathrm{~h}$, and then incubated overnight with primary mouse monoclonal antibody against V5 (1:5000; Invitrogen), mouse monoclonal antibody against 14-3-30 (1:10000; Abcam, Cambridge, MA, USA), or mouse monoclonal antibody against $\alpha$-tubulin (1:1000; Sigma, St Louis, MO, USA). After three washes in TBST, blots were incubated with HRP-conjugated goat anti-mouse secondary antibody (Jackson ImmunoResearch, West Grove, PA, USA) for $2 \mathrm{~h}$ and then washed in TBST six times for $10 \mathrm{~min}$ each. Blots were developed with enhanced chemiluminescence method (GE Healthcare, Piscataway, NJ, USA).

For $\alpha$-syn blots of stable cell lines, cells were sonicated in lysis buffer $(175 \mathrm{mM}$ $\mathrm{NaCl}, 50 \mathrm{mM}$ Tris- $\mathrm{HCl}$ (pH 7.4), $5 \mathrm{mM}$ EDTA, protease inhibitor cocktail (Roche Diagnostics)) and incubated with $1 \%$ Triton X-100 for $30 \mathrm{~min}$. After centrifugation, the supernatant was collected as the Triton X-100 soluble fraction. The Triton X-100 insoluble fraction was prepared by resuspension of the pellet in lysis buffer with $2 \%$ SDS. Samples were immunoblotted as described above, using a monoclonal anti- $\alpha$ syn antibody (1:1000; BD Biosciences). Densitometry was used to quantitate the multiple $\alpha$-syn bands (between $\sim 30$ and $70 \mathrm{kDa}$ ) in the insoluble fraction, which were normalized to tubulin levels.

Immunocytochemistry. Naive M17 cells, control stable cells, and 14-3-3overexpressing stable cell clones were fixed in $4 \%$ paraformaldehyde and permeabilized with Triton $X-100$. After incubation with $1 \%$ normal goat serum, cells were incubated overnight at $4^{\circ} \mathrm{C}$ with a mouse monoclonal antibody against the V5 epitope tag (Invitrogen), a rabbit polyclonal antibody against 14-3-3e (Abcam), a mouse monoclonal antibody against 14-3-3 $\theta$ (Abcam), or a rabbit polyclonal antibody against $\alpha$-syn (Cell Signaling, Danvers, MA, USA). Following washes in TBS, cells were incubated with cy3-conjugated goat anti-mouse or anti-rabbit secondary antibody (Jackson ImmunoResearch) for $2 \mathrm{~h}$ at room temperature. Nuclei were stained with Sytox Green (Invitrogen).

LDH assay. Cells were grown in pyruvate-free DMEM for a few days before plating in 24-well collagen-treated plates. The following day, cells were treated with varying concentrations of rotenone $\left(0,0.04,0.2,1,5\right.$, or $25 \mu \mathrm{M}$; Sigma) or MPP ${ }^{+}$ $(0,2,5$, or $10 \mathrm{mM}$; Sigma) in serum-free DMEM for 24,30 , or $48 \mathrm{~h}$. Toxicity was 
assayed by LDH release into media using the LDH assay kit (Roche). LDH release into media was normalized to total LDH release for each well.

RNA interference. The 14-3-3 $\theta$ shRNA pLKO.1 lentiviral constructs created by The RNA Consortium were purchased from Open Biosystems (Huntsville, AL, USA). Packaging of lentiviral shRNA constructs was performed by the UAB Neuroscience NINDS Protein Core (P30 NS47466). Four shRNA constructs were tested for their efficacy in reducing 14-3-30 protein expression, and two constructs were chosen for use in the rotenone toxicity experiments. M17 cells were infected with the empty vector pLKO.1 virus or one of the two 14-3-30 shRNA-containing pLKO.1 viruses in the presence of polybrene (Sigma). At $72 \mathrm{~h}$ after infection, infected cells were selected for in the presence of puromycin (Mediatech, Herndon, VA, USA). Selected cells were used for rotenone toxicity experiments as described under LDH assay.

Difopein experiments. Difopein-EYFP and scrambled difopein-EYFP were subcloned into the tetracycline-inducible lentiviral vector pSLIK. ${ }^{26} \mathrm{M} 17$ cells were infected with the difopein-EYFP or control-EYFP viruses in the presence of polybrene. At $72 \mathrm{~h}$ after infection, infected cells were selected for in the presence of hygromycin (EMD Biosciences, Gibbstown, NJ, USA). Two days before rotenone toxicity experiments, selected cells were treated with doxycycline (EMD Biosciences) at $10 \mu \mathrm{g} / \mathrm{ml}$ to induce difopein-EYFP or control-EYFP expression.

Generation and analysis of transgenic $C$. elegans. Expression plasmids, $\mathrm{P}_{\text {dat- }-1}:: 14-3-30, \mathrm{P}_{\text {dat }-1}:: 14-3-3 \gamma, \mathrm{P}_{\text {dat- }-1}:: 14-3-3 \varepsilon$, and $\mathrm{P}_{\text {dat }-1}:: \mathrm{ftt-2}$, as well as a marker, $P_{\text {unc }-54}::$ mCherry, were constructed by Gateway Technology (Invitrogen) and microinjected into the gonads of $C$. elegans strain UA44 (baln11;

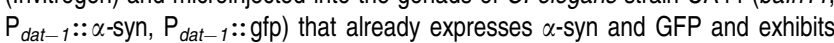
age-dependent $\alpha$-syn-induced degeneration in the dopaminergic neurons. ${ }^{27}$ Three resulting independent transgenic lines for each strain UA113 (baln11; baEx88, $\mathrm{P}_{\text {dat- } 1}:: 14-3-3 \theta, \mathrm{P}_{\text {unc-54 }}::$ mCherry), UA114 (baln11; baEx89, $\mathrm{P}_{\text {dat- } 1}:: 14-3-3 \gamma$, $\mathrm{P}_{\text {unc-54 }}:$ :mCherry), UA115 (baln11; baEx90, $\mathrm{P}_{\text {dat- } 1::}$ 14-3-3e, $\mathrm{P}_{\text {unc-54 }}::$

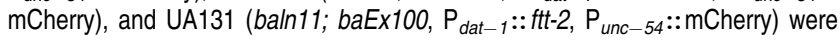
synchronized, grown at $20^{\circ} \mathrm{C}$, and analyzed for neuroprotection at days 7 and 10 (4- and 7-day-old adults). For each trial, 30 worms were transferred onto a $2 \%$ agarose pad and immobilized with $3 \mathrm{mM}$ levamisole, and the six anterior dopaminergic neurons (four CEP and two ADE dopaminergic neurons) were examined. In total, 90 animals from each of three 14-3-30, 14-3-3 $\gamma, 14-3-3 \varepsilon$, and $\mathrm{ftt}-2$, transgenic lines were analyzed ( 3 lines $\times 3$ trials of 30 animals/trial $=270$ total animals scored per 14-3-3 isoform). Worms displaying at least one degenerative change were scored as exhibiting degenerating neurons, as previously described. 27,40 The number of intact neurons per worm was also counted. To study a ftt-2 loss of function mutant, $C$. elegans knockout strain MT14355 (ftt-2(n4426)) was crossed into strain UA44 (baln11; $\mathrm{P}_{\text {dat-1 }}:: \alpha$-syn, $\mathrm{P}_{\text {dat- } 1:: \mathrm{gfp})}$ to generate the isogenic strain UA130 (baln11; ftt-2(n4426)). This strain was synchronized and analyzed as described above. Fluorescence microscopy was performed using a Nikon Eclipse E800 epifluorescence microscope equipped with Endow GFP HYQ filter cube (Chroma Technology, Rockingham, VT, USA), and images were captured with a Cool Snap CCD camera (Photometrics, Tucson, AZ, USA) with MetaMorph software (Molecular Devices, Downingtown, PA, USA).

Statistical analysis. GraphPad Prism 5 (GraphPad Inc., La Jolla, CA, USA) and SAS (SAS Inc., Cary, NC, USA) were used for statistical analysis of experiments. Quantitative PCR data were analyzed by two-way ANOVA, followed by post hoc least-squares means test. $\alpha$-Syn aggregation experiments were analyzed by one-way ANOVA, followed by post hoc Bonferroni's multiple comparison test. LDH assay experiments were analyzed by two-way ANOVA, followed by post hoc Bonferroni's multiple comparison test. $\alpha$-Syn blots were analyzed by one-way ANOVA, followed by post hoc Tukey's multiple comparison test. C. elegans data were analyzed by two-way ANOVA, followed by post hoc Bonferroni's multiple comparison test.

\section{Conflict of interest}

Talene Yacoubian and David Standaert have a pending patent application regarding the use of 14-3-3 proteins in the treatment of neurodegeneration. Sunny Slone, Adam Harrington, Shu Hamamichi, Jennifer Schieltz, Kim Caldwell, and Guy Caldwell declare no potential conflict of interest.
Acknowledgements. We thank Mary Ballestas and the UAB Neuroscience Core Center (P30 NS47466) for preparation of the 14-3-30 shRNA lentiviruses and the inducible difopein lentiviruses. We thank Pam McLean for providing the synT and synphilin plasmids. We also thank Dee Parsons for help with statistical analysis and Dan Carsen for review of the paper. This work was supported by an NIH NINDS K08 (NS060948-01) grant, by the American Parkinson Disease Association Postdoctoral Research Fellowship and George C Cotzias Memorial Fellowship, by the Parkinson's Association of Alabama, and by the MGH/MIT Morris Udall Center of Excellence in PD Research.

1. Dorsey ER, Constantinescu R, Thompson JP, Biglan KM, Holloway RG, Kieburtz K et al. Projected number of people with Parkinson disease in the most populous nations, 2005 through 2030. Neurology 2007; 68: 384-386.

2. Athanassiadou A, Voutsinas G, Psiouri L, Leroy E, Polymeropoulos MH, llias A et al. Genetic analysis of families with Parkinson disease that carry the Ala53Thr mutation in the gene encoding alpha-synuclein. Am J Hum Genet 1999; 65: 555-558.

3. Kruger R, Kuhn W, Muller T, Woitalla D, Graeber M, Kosel S et al. Ala30Pro mutation in the gene encoding alpha-synuclein in Parkinson's disease. Nat Genet 1998; 18: 106-108.

4. Polymeropoulos MH, Lavedan C, Leroy E, Ide SE, Dehejia A, Dutra A et al. Mutation in the alpha-synuclein gene identified in families with Parkinson's disease. Science 1997; 276: 2045-2047.

5. Zarranz JJ, Alegre J, Gomez-Esteban JC, Lezcano E, Ros R, Ampuero I et al. The new mutation, E46K, of alpha-synuclein causes Parkinson and Lewy body dementia. Ann Neurol 2004; 55: 164-173.

6. Singleton $A B$, Farrer M, Johnson J, Singleton A, Hague S, Kachergus $\mathrm{J}$ et al. alphaSynuclein locus triplication causes Parkinson's disease. Science 2003; 302: 841.

7. Irizarry MC, Growdon W, Gomez-Isla T, Newell K, George JM, Clayton DF et al. Nigral and cortical Lewy bodies and dystrophic nigral neurites in Parkinson's disease and cortical Lewy body disease contain alpha-synuclein immunoreactivity. J Neuropathol Exp Neurol 1998; 57: 334-337.

8. Spillantini MG, Schmidt ML, Lee VM, Trojanowski JQ, Jakes R, Goedert M. Alphasynuclein in Lewy bodies. Nature 1997; 388: 839-840.

9. Kirik D, Rosenblad C, Burger C, Lundberg C, Johansen TE, Muzyczka N et al. Parkinsonlike neurodegeneration induced by targeted overexpression of alpha-synuclein in the nigrostriatal system. J Neurosci 2002; 22: 2780-2791.

10. Lo Bianco C, Ridet JL, Schneider BL, Deglon N, Aebischer P. alpha-Synucleinopathy and selective dopaminergic neuron loss in a rat lentiviral-based model of Parkinson's disease. Proc Natl Acad Sci USA 2002; 99: 10813-10818.

11. Xu J, Kao SY, Lee FJ, Song W, Jin LW, Yankner BA. Dopamine-dependent neurotoxicity of alpha-synuclein: a mechanism for selective neurodegeneration in Parkinson disease. Nat Med 2002; 8: 600-606.

12. Zhou W, Schaack J, Zawada WM, Freed CR. Overexpression of human alpha-synuclein causes dopamine neuron death in primary human mesencephalic culture. Brain Res 2002; 926: 42-50.

13. Yacoubian TA, Cantuti-Castelvetri I, Bouzou B, Asteris G, McLean PJ, Hyman BT et al. Transcriptional dysregulation in a transgenic model of Parkinson disease. Neurobiol Dis 2008; 29: 515-528.

14. Dougherty MK, Morrison DK. Unlocking the code of 14-3-3. J Cell Sci 2004; 117 (Part 10): 1875-1884.

15. Mackintosh C. Dynamic interactions between 14-3-3 proteins and phosphoproteins regulate diverse cellular processes. Biochem J 2004; 381 (Part 2): 329-342.

16. Porter GW, Khuri FR, Fu H. Dynamic 14-3-3/client protein interactions integrate survival and apoptotic pathways. Semin Cancer Biol 2006; 16: 193-202.

17. Ostrerova N, Petrucelli L, Farrer M, Mehta N, Choi P, Hardy J et al. alpha-Synuclein shares physical and functional homology with 14-3-3 proteins. J Neurosci 1999; 19: 5782-5791.

18. Kawamoto Y, Akiguchi I, Nakamura S, Honjyo Y, Shibasaki H, Budka H. 14-3-3 proteins in Lewy bodies in Parkinson disease and diffuse Lewy body disease brains. J Neuropathol Exp Neurol 2002; 61: 245-253.

19. Shirakashi $Y$, Kawamoto $Y$, Tomimoto $H$, Takahashi R, Ihara M. alpha-Synuclein is colocalized with 14-3-3 and synphilin-1 in A53T transgenic mice. Acta Neuropathol 2006; 112: $681-689$.

20. Sato S, Chiba T, Sakata E, Kato K, Mizuno Y, Hattori $\mathrm{N}$ et al. 14-3-3eta is a novel regulator of parkin ubiquitin ligase. EMBO J 2006; 25: 211-221.

21. Kitada T, Asakawa S, Hattori N, Matsumine H, Yamamura Y, Minoshima S et al. Mutations in the parkin gene cause autosomal recessive juvenile parkinsonism. Nature 1998; 392: 605-608.

22. McLean PJ, Kawamata H, Hyman BT. alpha-Synuclein-enhanced green fluorescent protein fusion proteins form proteasome sensitive inclusions in primary neurons. Neuroscience 2001; 104: 901-912.

23. Betarbet R, Sherer TB, MacKenzie G, Garcia-Osuna M, Panov AV, Greenamyre JT. Chronic systemic pesticide exposure reproduces features of Parkinson's disease. Nat Neurosci 2000; 3: 1301-1306.

24. Betarbet R, Canet-Aviles RM, Sherer TB, Mastroberardino PG, McLendon C, Kim JH et al Intersecting pathways to neurodegeneration in Parkinson's disease: effects of the pesticide 
rotenone on DJ-1, alpha-synuclein, and the ubiquitin-proteasome system. Neurobiol Dis 2006; 22: 404-420.

25. Masters SC, Fu H. 14-3-3 proteins mediate an essential anti-apoptotic signal. J Biol Chem 2001; 276: 45193-45200.

26. Shin KJ, Wall EA, Zavzavadjian JR, Santat LA, Liu J, Hwang Jl et al. A single lentiviral vector platform for microRNA-based conditional RNA interference and coordinated transgene expression. Proc Natl Acad Sci USA 2006; 103: 13759-13764.

27. Cao S, Gelwix CC, Caldwell KA, Caldwell GA. Torsin-mediated protection from cellular stress in the dopaminergic neurons of Caenorhabditis elegans. J Neurosci 2005; 25: 3801-3812.

28. Berg D, Riess O, Bornemann A. Specification of 14-3-3 proteins in Lewy bodies. Ann Neurol 2003; 54: 135.

29. McFarland MA, Ellis CE, Markey SP, Nussbaum RL. Proteomics analysis identifies phosphorylation-dependent \{alpha\}-synuclein protein interactions. Mol Cell Proteomics 2008; 7: 2123-2137.

30. Chen XW, Sun SG, Cheng DB, Tian YY. Overexpression of 14-3-3 protein protects pheochromocytoma cells against 1-methyl-4-phenylpyridinium toxicity. Neurosci Bull 2006; 22: 281-287.

31. Ferguson AT, Evron E, Umbricht CB, Pandita TK, Chan TA, Hermeking $\mathrm{H}$ et al. High frequency of hypermethylation at the 14-3-3 sigma locus leads to gene silencing in breast cancer. Proc Natl Acad Sci USA 2000; 97: 6049-6054.

32. Suzuki H, Itoh F, Toyota M, Kikuchi T, Kakiuchi H, Imai K. Inactivation of the 14-3-3 sigma gene is associated with $5^{\prime} \mathrm{CpG}$ island hypermethylation in human cancers. Cancer Res 2000; 60: 4353-4357.

33. Leffers $\mathrm{H}$, Madsen $\mathrm{P}$, Rasmussen $\mathrm{HH}$, Honore $\mathrm{B}$, Andersen $\mathrm{AH}$, Walbum E et al. Molecula cloning and expression of the transformation sensitive epithelial marker stratifin. A membe of a protein family that has been involved in the protein kinase $C$ signalling pathway. J Mol Biol 1993; 231: 982-998.
34. Nomura M, Shimizu S, Sugiyama T, Narita M, Ito T, Matsuda H et al. 14-3-3 Interacts directly with and negatively regulates pro-apoptotic Bax. J Biol Chem 2003; 278: 2058-2065.

35. Morton DG, Shakes DC, Nugent S, Dichoso D, Wang W, Golden A et al. The Caenorhabditis elegans par-5 gene encodes a 14-3-3 protein required for cellular asymmetry in the early embryo. Dev Biol 2002; 241: 47-58.

36. Brunelli $L$, Cieslik KA, Alcorn JL, Vatta M, Baldini A. Peroxisome proliferator-activated receptor-delta upregulates 14-3-3 epsilon in human endothelial cells via CCAAT/enhancer binding protein-beta. Circ Res 2007; 100: e59-e71.

37. Liou JY, Lee S, Ghelani D, Matijevic-Aleksic N, Wu KK. Protection of endothelial survival by peroxisome proliferator-activated receptor-delta mediated 14-3-3 upregulation. Arterioscler Thromb Vasc Biol 2006; 26: 1481-1487.

38. Wu JS, Cheung WM, Tsai YS, Chen YT, Fong WH, Tsai HD et al. Ligand-activated peroxisome proliferator-activated receptor-gamma protects against ischemic cerebral infarction and neuronal apoptosis by 14-3-3epsilon upregulation. Circulation 2009; 119: 1124-1134.

39. Masliah E, Rockenstein E, Veinbergs I, Mallory M, Hashimoto M, Takeda A et al. Dopaminergic loss and inclusion body formation in alpha-synuclein mice: implications for neurodegenerative disorders. Science 2000; 287: 1265-1269.

40. Cooper AA, Gitler AD, Cashikar A, Haynes CM, Hill KJ, Bhullar B et al. Alpha-synuclein blocks ER-Golgi traffic and Rab1 rescues neuron loss in Parkinson's models. Science 2006; 313: 324-328.

Cell Death and Disease is an open-access journal published by Nature Publishing Group. This article is licensed under a Creative Commons Attribution-Noncommercial-No Derivative Works 3.0 license. To view a copy of this license, visit http:// creativecommons.org/licenses/by-nc-nd/3.0/

Supplementary Information accompanies the paper on Cell Death and Disease website (http://www.nature.com/cddis) 